$\S=-1$

\title{
Experimental Study on Strength of Concrete Partially Replacing Chiton shell as Fine Aggregate
}

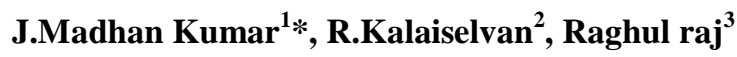 \\ ${ }^{1}$ Department of civil Engineering, vel tech high tech Dr.Rangarajan Dr.Sakunthala Engineering College, \\ *Corresponding author E-mail: jmk.dreambuilde@gmail.com
}

\begin{abstract}
The most widely used material in the world is concrete, consequently there is a large requirement for raw material of concrete such as Fine Aggregate, Coarse Aggregate and cement. the huge extraction of the aggregate for manufacturing of concrete as serious effect on the environment due to depletion of natural resources and pollution. This affects the eco system to great extent. Hence the project deals with finding replacement for the existing raw material used in concrete by replacing the fine aggregate from river which is largely used in construction by chiton shell. Sea shell is the corpus of the marine organism. The sea shell has been grinded to $4.75 \mathrm{~mm}$ and then replaced in the concrete. M20 mix was used and cubic specimen were casted for 5 different percentage of partial replacement as $0 \%, 5 \%, 10 \%$, $20 \%$, and $25 \%$. All the specimens are tested for $7 \& 28$ days compressive, flexural and split tensile strength. it has been noted that the highest strength is obtained for $25 \%$ replacement of chiton shell. it was also observed that addition of sea shell power in concrete reduced workability hence superplasticizer were added to improve the consistency.
\end{abstract}

Keywords: chiton shell, Partial coarse \& fine aggregate replacement, Tensile strength, Compressive strength

\section{[1]Introduction}

The growing demand for the infrastructural development in India and around the world create a demand for the raw material used for the manufacturing of cement. Concrete is the premier civil engineering construction material. The raw material required for the manufacturing of concrete are aggregates, water and admixture(s). Among all the raw materials, aggregates form the major part. 1.5 billion tons of aggregate are produced each year in India. Recent investigation using various type of Indian sea shells has indicated that not only it can be utilizated as a material to construct but will also lead to reduction in the problem of disposing waste material. Replacements of various sea shell as Aggregate as been experimented before. The investigation of various physical characteristics of sea shell in the formulation of concrete it can be used as cement base " by Mohamed Barbachi, et al.,"[1]. Replacement of sea shell as coarse aggregate in 10\%, 20\% and 30\% as shown there was no change is the strength upto $20 \%$ and slight decrease in the strength occurred after $30 \%$ " as studied by P.Sasikumar et al.,[2]". Another study involving replacement of sea shell as course aggregate with fly ash replacement about $25 \%$ showed the strength is unchanging upto $10 \%$ replacement of sea shell and $25 \%$ of fly ash but strength decreases afterward "as experimented by Vignesh. S, et al.,[3]". the explanatory study done using partial replacement of fine aggregate using cockle shell show a increase in the strength up to $30 \%$ "N.Devendran, et al.,[4]". The replacement of sea shell not only improved by comprasion strength but as improves split tensile strength "as studied by V. Mohanalakshmi, et al.,[5]". The investigator carried out research on the mechanical properties of sea shell found that the young's modulus increases with age " as researched by MonitaOliviaa, et al.,[6]". The replacement of sea shell reduces workability "as investigateded by Nahushananda Chakravarthy H.G, et al.,[7]" . the decrease in the workability was due to the shape and interior texture of the sea shell "as investigated by Vijay Kumar, et al.,[8]". The density of the concrete also reduced due to the addition of sea shell by about $45 \%$ " M. Mageswari, et al.,[9]". There were also experiments on using industrial wastes form food industries such as oyster shells" as experimented by Eun-Ik Yang et al., [10]"

\section{Methods and Materials}

\subsection{General}

In this chapter, we are going to explain about methodology of the project and materials used. Material test have done and is explained in the following chapter.

\subsection{Seashell}

Sea shells are fossilized material obtained by decomposition of dead animal and plants. In some cases sea shells are serving as a natural defense mechanism for various aquatic creatures. The major constituent of sea shell is calcium carbonate there for it as a good mechanical property and can be used to replace natural sand as fine aggregate in concrete.

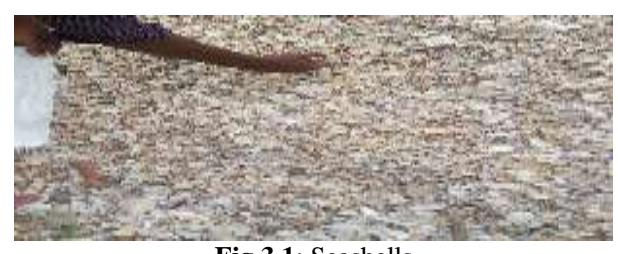

Fig 3.1: Seashells 


\subsection{Cement}

The most regular cement used is an ordinary Portland cement. The Ordinary Portland Cement of 53 grade conforming to IS: 122691987 is used. A number of tests were experimented on cement; some of them are setting tests, Specific gravity, etc

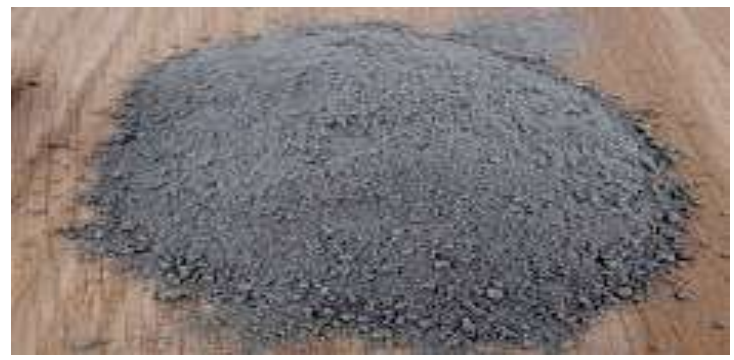

Fig 3.2: Cement

Table 1: Properties of cement

\begin{tabular}{|l|l|l|}
\hline S.No & Physical Properties & Result \\
\hline 1 & Specific gravity & 3.12 \\
\hline 2 & Consistency & $28 \%$ \\
\hline 3 & Fineness modulus & 2.37 \\
\hline 4 & Initial setting time & 48 minutes \\
\hline 5 & Final setting time & 712 minutes \\
\hline
\end{tabular}

\subsection{Aggregates}

$20 \mathrm{~mm}$ aggregate as been used and the size of fine aggregate used is of zone 2. The aggregates are tested and the results are as follows

\subsubsection{Fine Aggregate:}

The sieve analysis is conducted to find the size of the sand and its zone.The analysis is done with $500 \mathrm{~g}$ of sand in an automatic sieve shaker for about 5 minutes with the sieve dishes are arranged from $10 \mathrm{~mm}$ to 150 microns down the order of sieve shaker. Based on the analysis the fineness modulus obtained is 2.46 . Specific gravity of fine aggregate is 2.51 .

According to IS 2386 - 1963, Fineness modulus ranges are

Fine sand : $\quad 2.3-2.55$

Medium sand: $\quad 2.59-2.87$

Coarse sand : $\quad 2.85-3.0$

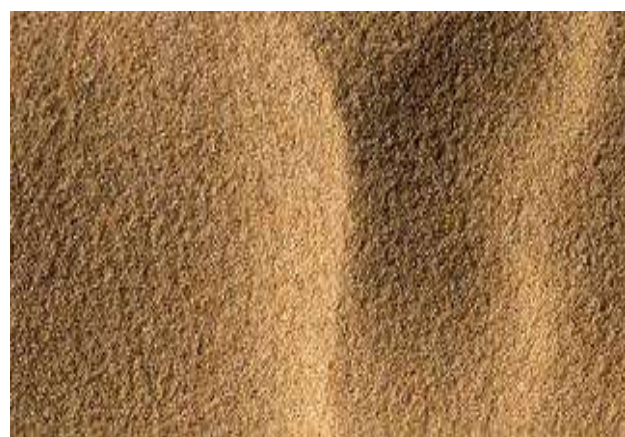

Fig 3.3: Fine aggregate

\subsubsection{Coarse Aggregate:}

The sieve analysis for gravel is done to find out its size and zone. The partical which remains from $80 \mathrm{~mm}$ to $4.75 \mathrm{~mm}$ are termed as coarse aggregate. The test was carried out with $5 \mathrm{Kg}$ of aggregate by sieve shaker for about 15 minutes with the sieve dishes are arranged from $40 \mathrm{~mm}$ to 150 microns down the order of sieve shaker. Based on experiment conducted, the fineness modulus obtained as 7.012 which are in zone - II conforming to IS $383-$ 1970. Specific gravity is found to be 2.67 .

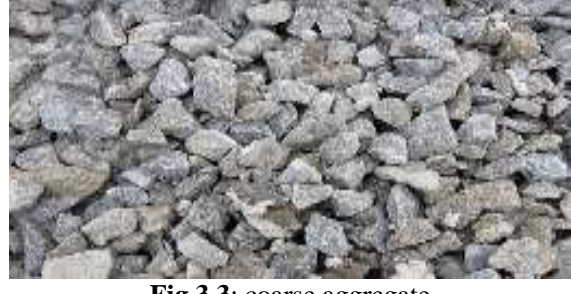

Fig 3.3: coarse aggregate

\section{Test and Results}

\subsection{Compressive Strength Test}

Compressive test is conducted to establish the compressive strength of the test sample. first surface moisture was removed by drying in air. For each ratio of replacement of chiton shell three cubes were tested in the compression testing machine for both 7 days $\& 28$ days strength. the are shown in the table- 2 .

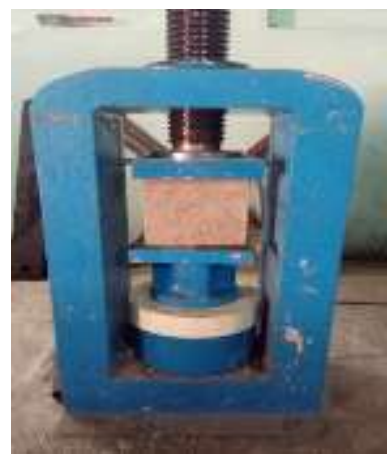

Fig 4.1: compressive strength test of concrete

Table 2: Compressive Strength Result of Concrete after Curing of $7^{\text {th }}$ Day

\begin{tabular}{|r|r|r|}
\hline S.NO & $\begin{array}{l}\text { PERCENTAGE (\%)OF } \\
\text { SEASHELL }\end{array}$ & $\begin{array}{l}\text { 7th day COMPRESSIVE } \\
\text { STRENGTH (KN) }\end{array}$ \\
\hline 1 & 0 & 401 \\
\hline 2 & 5 & 392 \\
\hline 3 & 10 & 420 \\
\hline 4 & 15 & 391 \\
\hline 5 & 20 & 479 \\
\hline 6 & 25 & 507 \\
\hline
\end{tabular}

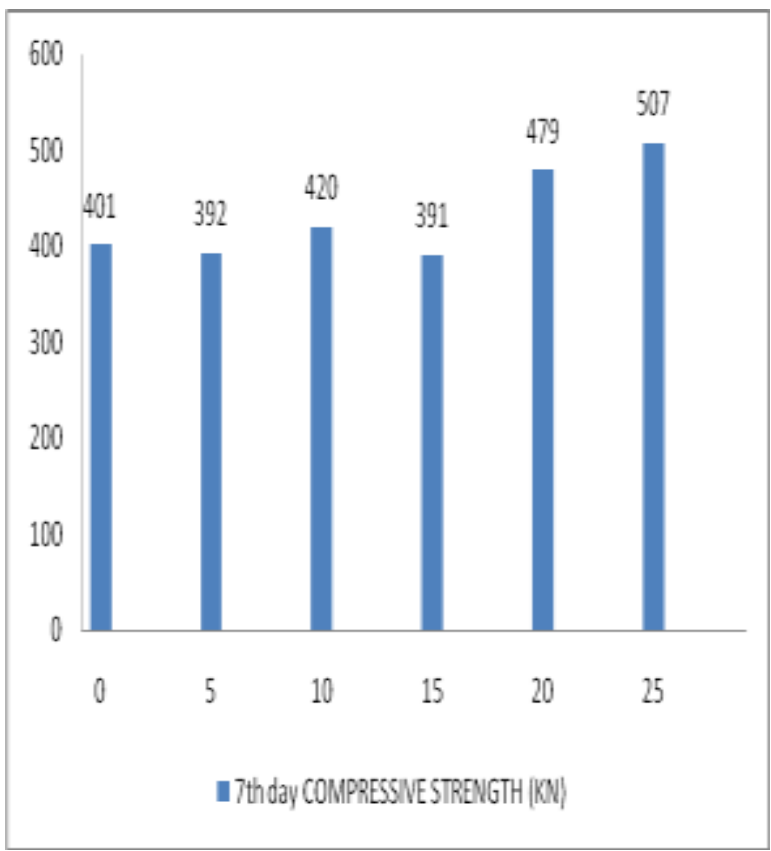


Table 3: Compressive Strength Result of Concrete after Curing of $28^{\text {th }}$ Day

\begin{tabular}{|c|c|c|}
\hline S.NO & $\begin{array}{c}\text { PERCENTAGE (\%)OF } \\
\text { SEASHELL }\end{array}$ & $\begin{array}{c}\text { COMPRESSIVE } \\
\text { STRENGTH (KN) } \\
\mathbf{2 8}^{\text {th }} \text { day }\end{array}$ \\
\hline 1 & 0 & 590 \\
\hline 2 & 5 & 589 \\
\hline 3 & 10 & 592 \\
\hline 4 & 15 & 613 \\
\hline 5 & 20 & 645 \\
\hline 6 & 25 & 748 \\
\hline
\end{tabular}

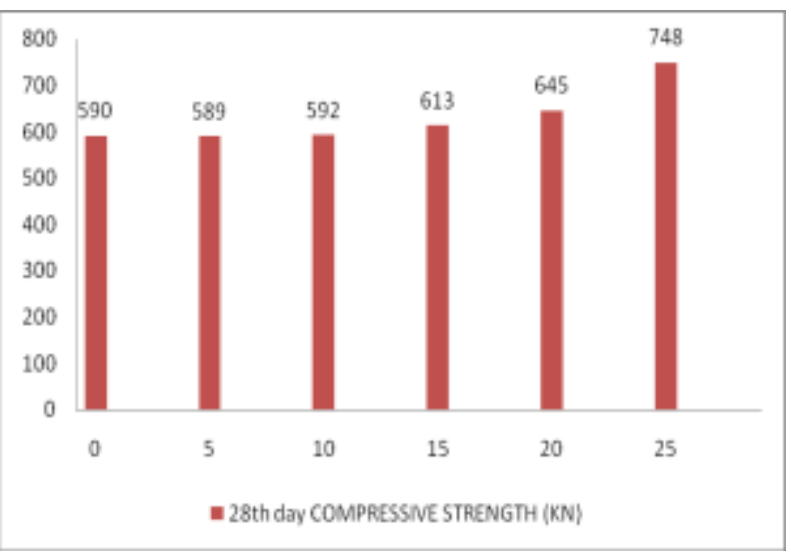

\subsection{Split Tensile Strength Test}

It is a well known fact that concrete is stronger in compression and week is tension hence it is important to measure the tensile capacity of concrete.

Table 4: split tensile Strength Result of Concrete after Curing of $7^{\text {th }}$ Day

\begin{tabular}{|c|c|c|}
\hline Table 4: split tensile Strength Result of Concrete after Curing of $7^{\text {Day }}$ \\
S.NO & $\begin{array}{c}\text { PERCENTAGE (\%)OF SEA- } \\
\text { SHELL }\end{array}$ & $\begin{array}{c}\text { SPLIT TENSILE } \\
\text { STRENGTH LOADS } \\
\text { (KN) }\end{array}$ \\
\hline 1 & 0 & 76 \\
\hline 2 & 5 & 74 \\
\hline 3 & 10 & 80 \\
\hline 4 & 15 & 84 \\
\hline 5 & 20 & 72 \\
\hline 6 & 25 & 89 \\
\hline
\end{tabular}

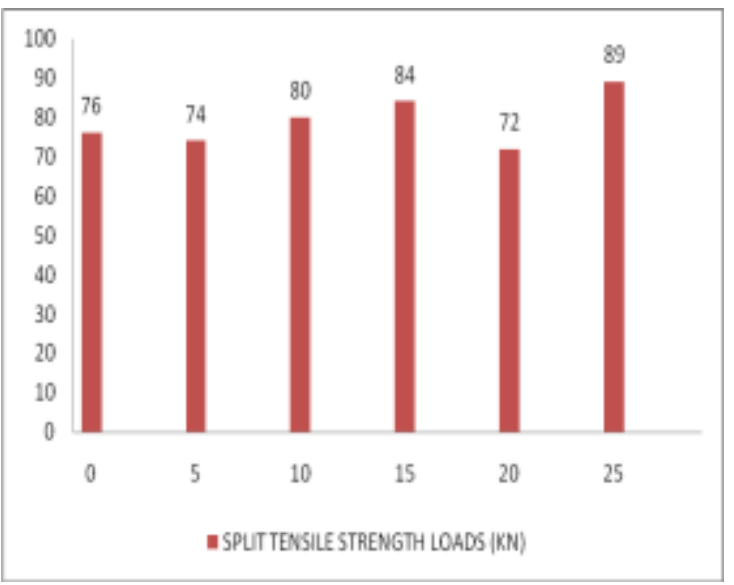

Table 5: split tensile Strength Result of Concrete after Curing of $28^{\text {th }}$ Day

\begin{tabular}{|c|c|c|}
\hline S.NO & $\begin{array}{c}\text { PERCENTAGE (\%)OF SEA- } \\
\text { SHELL }\end{array}$ & $\begin{array}{c}\text { SPLIT TENSILE } \\
\text { STRENGTH LOADS } \\
\text { (KN) }\end{array}$ \\
\hline 1 & 0 & 127 \\
\hline 2 & 5 & 123 \\
\hline 2 & 10 & 136 \\
\hline 4 & 15 & 151 \\
\hline 3 & 20 & 148 \\
\hline 6 & 25 & 158 \\
\hline
\end{tabular}

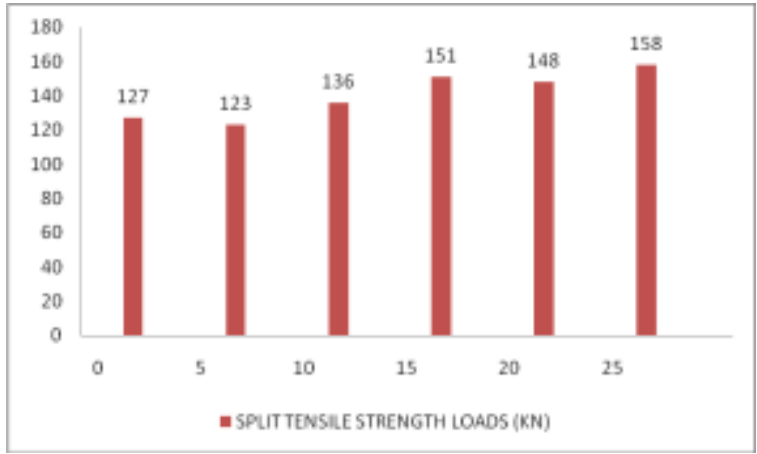

\subsection{Flexural Strength Test}

Flexural strength test is used to measure the tensile strength of concrete. It is a measure maximum load at which the flexural failure of the specimen occurs.the specimen adopted for the test is $100 \mathrm{~mm} \times 100 \mathrm{~mm} \times 500 \mathrm{~mm}$ concrete beam.Two specimen were subjected to tested for the age of 28 Days. the flexural strength of concrete was found by Two points loading The Table below shows the Flexural Strength for 28 days cubes.

Table 6: Flexural strength test result of concrete after curing of $7^{\text {th }}$

\begin{tabular}{|c|c|c|}
\hline \multirow{2}{*}{ S.NO } & $\begin{array}{c}\text { PERCENTAGE }(\%) \text { OF SEA- } \\
\text { SHELL }\end{array}$ & $\begin{array}{c}\text { Flexural Strength }(\mathrm{KN}) \\
\mathbf{7}^{\text {th }} \text { day }\end{array}$ \\
\hline 1 & 0 & 1 \\
\hline 2 & 5 & 1 \\
\hline 3 & 10 & 1 \\
\hline 4 & 15 & 2 \\
\hline 5 & 20 & 2 \\
\hline 6 & 25 & 3 \\
\hline
\end{tabular}

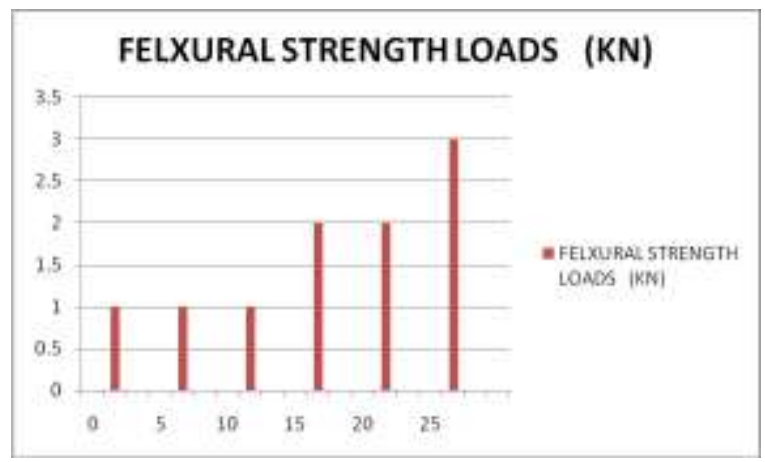

Table 7: Flexural strength test result of concrete after curing of $28^{\text {th }}$

\begin{tabular}{|c|c|c|}
\hline S.NO & $\begin{array}{c}\text { PERCENTAGE (\%)OF } \\
\text { SEASHELL }\end{array}$ & $\begin{array}{c}\text { Flexural Strength (KN) } \\
\mathbf{2 8}^{\text {th }} \mathbf{\text { day }}\end{array}$ \\
\hline 1 & 0 & 2 \\
\hline 2 & 5 & 2 \\
\hline 2 & 10 & 3 \\
\hline 3 & 15 & 3 \\
\hline 3 & 20 & 3 \\
\hline 4 & 25 & 5 \\
\hline
\end{tabular}

FELXURALSTRENGTHLOADS (KN)

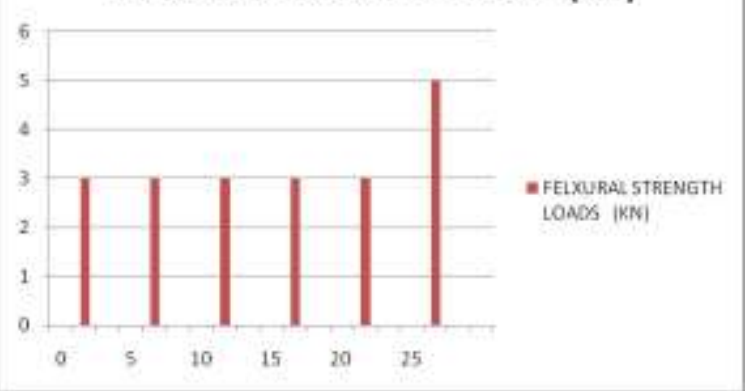




\section{Conclusions}

The concrete was prepared for the M25 grade concrete with partial replacement of fine aggregate with cockal shell in various percentage of $0 \%, 5 \%, 10 \%, 15 \%, 20 \%, 25 \%$. The specimens were casted for 7 days, 14 days and 28days were tested. The results are as presented below

From the above results following conclusion are made

1) The test result show $39.5 \%$ increase in the compressive strength in comparison with the conventional concrete with $29.5 \%$ partial replacement of sea shell for fine aggregate.

2) The maximum flexural strength for partial replacement of sea shell in fine aggregate by $28.9 \%$ is found to be greater than the conventional concrete.

3) A reduction in the workability was observed when fine aggregate was partially replaced by sea shell.

4) The optimum percentage of replacement was found to be $29.9 \%$.

\section{Reference}

[1] Sasikumar.P , C.Suriyakumar , P.Yuvaraj , B.Madhankumar , Er.K.Jeganmohan, A Partial Replacement for Coarse Aggregate by Sea Shell and Cement by Lime in Concrete Imperial Journal of Interdisciplinary Research 2017.

[2] Vignesh.S ,Structural Engineering A Partial Replacement for Coarse Aggregate by Seashell and Cement ByFlyash In ConcreteNational Conference on Research Advances in Communication, Computation, Electrical Science and Structures

[3] Devendran.N.,Experimental Study on Strengthening Of Concrete by Replacing Seashell and Flyash, International Journal of Computational Engineering Research 2017

[4] Mohanalakshmi.V Ms. S. Indhu Developing Concrete using Sea Shell as a FineAggregate International Journal for Innovative Research in Science \&Technology|Volume 3(10) 2017

[5] Monita Olivia, AnnisaArifanditaMifshella, LitaDarmayanti, Mechanical properties of seashell concrete The 5th International Conference of Euro Asia Civil Engineering Forum 2015

[6] Nahushananda,Chakravarthy H.G and TatendaMutusvaInvestigation Of Properties Of Concrete With Seashells As A Coarse Aggregate Replacement In Concrete ,International Journal of Science and Technology ISSN 2454-5880

[7] Vijay Kumar and Deepak JainUse of Sea Shells as Aggregate in Concrete IJSRD - International Journal for Scientific Research \& Development| Vol.3, Issue 03, 2015

[8] Mageswari.M C.R.Manoj, M.Siddarthan, T.P.Saravanan,G.Princepatwa, To Increase The Strength Of Concrete By AddingSeashell As Admixture International Journal of Advanced Research in Civil,Structural,Environmental and Infrastructure Engineering and Developing, 2016

[9] Khaled Boudjellal, Mohamed Bouabaz, Mohamed Barbachi1, AbdellatifImad, FaouazJeffali, Physical characterization of sea shell for a concrete formulation (2017) 